\title{
Effect of subchronic in vivo exposure to nitrogen dioxide on lung tissue inflammation, airway microvascular leakage, and in vitro bronchial muscle responsiveness in rats
} Pasquale Chitano, Vanda Rado, Antonino Di Stefano, Alberto Papi, Anna Boniotti,
Gianna Zancuoghi, Piera Boschetto, Maria Romano, Mario Salmona, Adalberto Ciaccia,
Leonardo Michele Fabbri, Cristina Elisabetta Mapp

\begin{abstract}
Objectives-In a previous study on bronchoalveolar lavage fluid from rats exposed in vivo for seven days to $10 \mathrm{ppm}$ nitrogen dioxide $\left(\mathrm{NO}_{2}\right)$, it has been shown that there is an influx of macrophages into the airways. The present study investigated the effect of seven day exposure to $10 \mathrm{ppm} \mathrm{NO}$, on: (a) lung tissue inflammation and morphology; (b) airway microvascular leakage; (c) in vitro contractile response of main bronchi.

Methods-Lung tissue was studied by light microscopy, after fixing the lungs by inflation with $4 \%$ formalin at a pressure of $20 \mathrm{~cm} \mathrm{H}_{2} \mathrm{O}$. Microvascular leakage was measured by extravasation of Evans blue dye in the larynx, trachea, main bronchi, and intrapulmonary airways. Smooth muscle responsiveness was evaluated by concentration-response curves to acetylcholine $\left(10^{-9}-10^{-3} \mathrm{M}\right)$, serotonin $\left(10^{-9}-10^{-4} \mathrm{M}\right)$, and voltage-response curves (12-28 V) to electrical field stimulation.
\end{abstract}

Results-Histology showed an increased total inflammation at the level of respiratory bronchioles and alveoli. No influx of inflammatory cells was found in the main bronchi. A loss of cilia in the epithelium of small airways and ectasia of alveolar capillaries was also found. By contrast, no alterations to microvascular permeability or modification of bronchial smooth muscle responsiveness was found.

Conclusions-Subchronic exposure to 10 ppm $\mathrm{NO}_{2}$ causes airway inflammation and structural damage, but does not cause any persistent alteration to microvascular permeability or bronchial smooth muscle responsiveness in rats.

(Occup Environ Med 1996;53:379-386)

Keywords: airway smooth muscle; lung histology; vascular permeability

Nitrogen dioxide $\left(\mathrm{NO}_{2}\right)$ is a common component of environmental air pollution produced by processes involving high temperatures. Its general environmental concentration may reach values of $0.5 \mathrm{ppm}$ in urban areas, but its concentration at the workplace may reach values of up to $500 \mathrm{ppm}$ in those specific zones where welding arcs and blow torches are used. ${ }^{1-3}$

Many studies have reported injurious effects of exposure to $\mathrm{NO}_{2}$ on the structure, function, and biochemistry of the respiratory system. In particular, exposure to $\mathrm{NO}_{2}$ causes pulmonary inflammation, lung oedema, and airway hyperresponsiveness. ${ }^{3-5}$

Airway inflammation is a consistent finding both in animals and in humans exposed to $\mathrm{NO}_{2}$. It is more pronounced in peripheral airways and alveoli. In animals, it is mainly characterised by neutrophil and macrophage infiltration, whereas in humans an increased number of mast cells and lymphocytes have been reported in bronchoalveolar lavage fluid. ${ }^{346}$

Lung oedema has been shown in animals to be associated with cellular infiltration into the airways. It occurs mainly during early exposure to $\mathrm{NO}_{2}$ and is correlated with the degree of exposure, but it has also been reported after chronic exposures. ${ }^{378}$

Airway hyperresponsiveness caused by $\mathrm{NO}_{2}$ has been reported in healthy, bronchitic, and asthmatic subjects, ${ }^{4910}$ and in guinea pigs, ${ }^{11} 12$ although several inconsistencies exist in those studies. Whether the $\mathrm{NO}_{2}$ effect on airway responsiveness involves alterations in bronchial smooth muscle responsiveness has not yet been elucidated. Indeed, contradictory results have also been reported in the few studies performed on responsiveness of bronchial smooth muscle exposed in vitro. ${ }^{13-15}$

We have recently established an animal model of inflammation induced by $\mathrm{NO}_{2}$ in which we showed an increase in the number of macrophages in bronchoalveolar lavage fluid from rats exposed for seven days to $10 \mathrm{ppm}$ $\mathrm{NO}_{2}{ }^{16}$ In the present study we wanted to investigate whether the inflammatory response produced by $\mathrm{NO}_{2}$ in this model was associated with structural alterations of the lung tissue, with persistent increase of microvascular leakage and of bronchial smooth muscle responsiveness. Indeed, the contemporary induction by $\mathrm{NO}_{2}$ of pulmonary inflammation, airway microvascular leakage, and airway smooth muscle hyperresponsiveness, which are the three most relevant features of asthma, would supply a suitable animal model to study pathological mechanisms possibly involved in asthma. We therefore studied: (a) the inflammatory response in lung tissue and the morphological alterations of airway and 
parenchimal structural components by lung histology; $(b)$ the microvascular leakage in the airways by direct measurement; $(c)$ the in vitro bronchial smooth muscle contractile response.

\section{Materials and methods}

ANIMALS AND EXPOSURE TO NO

Sprague-Dawley CD rats weighing 200-300 g (Charles River) were used in this study. The procedures involving animal care and exposure were conducted conforming with our institutional guidelines, which comply with national and international laws and policies (EEC Council directive 86/609; NIH guide for care and use of laboratory animals, NIH Publ No 85-23, 1985). Specific protocols and procedures were approved by the committee on animal care of the Universities of Ferrara or Padova.

Twenty rats were exposed to $10 \mathrm{ppm} \mathrm{NO}_{2}$ for seven days, and 24 control animals were exposed to filtered air for the same period. The exposure was carried out as previously described. ${ }^{17}$ Briefly, rats were exposed in a stainless steel chamber $\left(3.96 \mathrm{~m}^{3}\right)$, with conditioned air at a mean (SD) of 21 (1) ${ }^{\circ} \mathrm{C}$ and $50 \%(10 \%)$ humidity. Cylinders containing $1 \% \mathrm{NO}_{2}$ in $\mathrm{N}_{2}$ (SIO, Milan, Italy) were used as the source of $\mathrm{NO}_{2}$. The $\mathrm{NO}_{2}$ concentration in the chamber was measured by a Monitor Labs nitrogen oxides analyser 8840 (Denver, CA, USA), connected to an Olivetti PCS 86 computer system (Ivrea, Italy), and to a control module MPS 2000 Micros (Treviso, Italy). This computerised system recorded and kept constant the $\mathrm{NO}_{2}$ concentration in the chamber for the duration of the exposure, with a closed loop feedback and thus regulated the flow of $\mathrm{NO}_{2}$ and air from the cylinders to the exposure chamber. Gas concentrations varied less than $1 \%$ from the nominal value.

Rats were killed 24 hours after the end of the exposure to investigate any persistent effect. At the end of the exposure, the animals underwent one of the following experimental protocols.

\section{LUNG HISTOLOGY}

For histological studies, the animals were killed and the heart and lungs were gently extracted from the chest. The lungs were then inflated and fixed by endotracheal instillation of $4 \%$ formaldehyde in sodium phosphate buffer for six hours, at a constant pressure of $20 \mathrm{~cm} \mathrm{H}_{2} \mathrm{O}$ at room temperature. After fixation, the left lung was cut into two halves (medial and lateral) along its midsagittal plane. These two preparations were then dehydrated in ethanol, passed through xylene, and embedded in paraffin. A section $6 \mu \mathrm{m}$ thick was obtained from the surface of each block, and stained with haematoxylin-eosin for analysis by light microscopy, with a Jenamed 30G0040 microscope.

Neutrophils were assessed in the main lobar bronchus (in an area $20 \mu \mathrm{m}$ beneath the epithelial basement membrane), and in the small airways (in the whole wall). The cells were counted at a magnification of $\times 780$ in contiguous non-overlapping high power fields until all the available area was covered. About seven high power fields were analysed for each section and the final cell count relative to each animal was expressed as the average number of cells per high power field counted in the two sections.

Total inflammation was assessed at a magnification of $\times 400$ according to the method of Cosio et $a l^{18}$ and studied in the main lobar bronchus, in small airways, and at the level of respiratory bronchioles and alveoli-that is, bronchioles with a discontinuous airway wall and the surrounding alveolar regions. This method allows for a semiquantitative assessment, in histological preparations, of a given event that produces alterations at tissue level. The occurrence of an event $\mathrm{X}$ under examination is classified according to a discrete scalethat is, the range of all possible intensities of $\mathrm{X}$ is divided into classes which score from 0 (absence of $\mathrm{X}$ ) to $\mathrm{N}$ (maximum intensity of $\mathrm{X})$. Then $\mathrm{X}$ is measured several times and each measurement is assigned to a given class of intensity. We investigated the intensity of total inflammation in the lung tissue with a subdivision into four classes: 0 , absence of inflammatory cell infiltrate; 1 , presence of a few cells (low inflammation); 2, presence of several cells (moderate inflammation); and 3, massive cellular infiltration (high inflammation). Therefore, an appropriate score from 0 to 3 was assigned to each airway or bronchiolar-alveolar area examined. The scores of each area were then summed and the results were expressed as the percentage of the maximum possible score for each case (maximum cellular infiltration).

The same method (score from 0 to 3 ) was used to assess loss of cilia by the epithelial cells in the small airways and results were expressed as a percentage of the maximum damage (no presence of cilia).

In the lung parenchyma, as an index of alveolar structural damage, we measured the mean linear intercept $(\mathrm{Lm})$, defined as the mean linear distance between alveolar septa. To do this we used a microscope with a $\times 10$ objective and $a \times 10$ eyepiece according to the modified method of Thurlbeck. ${ }^{19}$

\section{AIRWAY MICROVASCULAR LEAKAGE}

To assess vascular permeability, animals were premedicated with diazepam $(3 \mathrm{mg} / \mathrm{kg}$ ) by intraperitoneal injection and anaesthetised with $0.5 \mathrm{ml}$ of Leptofen (containing $1 \mathrm{mg}$ droperidiol and $0.032 \mathrm{mg}$ fentanyl citrate) by intramuscular injection. Then the jugular veins were exposed and $30 \mathrm{mg} / \mathrm{kg}$ of Evans blue dye $(30 \mathrm{mg} / \mathrm{ml}$ in $0.9 \% \mathrm{NaCl}$, filtered through a $0.22 \mu \mathrm{m}$ Millipore filter) were injected intravenously as a tracer. Five minutes later, the chest was opened and a cannula was inserted into the ascending aorta through the left ventricle to perfuse the animal's vascular system. Perfusion was carried on for two minutes under a pressure of $100 \mathrm{~mm} \mathrm{Hg}$ with $100 \mathrm{ml}$ of $0.9 \% \mathrm{NaCl}$ solution $(\mathrm{pH} \mathrm{5.5)}$ at room temperature. Blood and saline were drained through an incision made in the right 
atrium. Thereafter, the larynx, trachea, main bronchi, and lungs were removed and separated from each other. The intrapulmonary airways were stripped of the parenchyma by gently scraping with a razor blade. Excess fluid was removed by squeezing between filter papers and the tissue wet weight was measured.

Evans blue dye was extracted from the tissues by incubating each sample overnight in 2 $\mathrm{ml}$ of formamide at $50^{\circ} \mathrm{C}$. The concentration of Evans blue dye was measured by light absorbance against a formamide blank at a wavelength of $620 \mathrm{~nm}$ with a DU-40 spectrophotometer (Baclman Instruments, Irvine, CA, USA), and by interpolation on a standard curve of dye in formamide in the range 0.5-10 $\mu \mathrm{g} / \mathrm{ml}$. Final results were expressed as $\mathrm{ng}$ of Evans blue dye per mg of wet weight tissue.

\section{BRONCHIAL SMOOTH MUSCLE RESPONSE IN}

VITRO

To study smooth muscle response in vitro, animals were killed and the trachea and lungs were rapidly removed and immersed in oxygenated Krebs-Henseleit solution containing the following $(\mathrm{mM}): \mathrm{NaCl} 118.3, \mathrm{KCl} \mathrm{4.7}$, $\mathrm{MgSO}_{4} 1 \cdot 2, \mathrm{KH}_{2} \mathrm{PO}_{4} 1 \cdot 2, \mathrm{NaHCO}_{3} 25 \cdot 0$, $\mathrm{CaCl}_{2} 2 \cdot 5$, and $\mathrm{d}-(+)$-glucose $11 \cdot 1$. The two main bronchi were dissected free of loose connective tissue and a ring was prepared from each. The rings were mounted in double jacketed glass organ baths filled with KrebsHenseleit solution, that was maintained at $37^{\circ} \mathrm{C}$ and aerated continuously by bubbling it with a mixture of $95 \% \mathrm{O}_{2}$ and $5 \% \mathrm{CO}_{2}$, which produced a $\mathrm{pH}$ of $7 \cdot 4$. As it has been reported that altered smooth muscle contractility may consist of increased shortening not associated with any alteration in the ability to develop tension, ${ }^{20}$ this study was performed both isometrically and isotonically, the two techniques which allow investigation of these two types of muscle response. The rings were therefore connected to a force displacement transducer (Grass FTO3) or to an isotonic transducer (Basile 7006), and allowed to equilibrate for 90 minutes with a resting tension of $300 \mathrm{mg}$. During equilibration the medium was changed every 20 minutes. We continuously monitored isometric tension or isotonic shortening and recorded the responses on a paper polygraph (Battaglia Rangoni KV380).

For each ring in both isometric and isotonic conditions we performed cumulative concentration-response curves to acetylcholine (ACh) from $10^{-9}$ to $10^{-3} \mathrm{M}$, serotonin (5-HT) from $10^{-9}$ to $10^{-4} \mathrm{M}$, and in isometric conditions voltage-response curves $(12-28 \mathrm{~V})$ to electrical field stimulation with a 10 second stimulus ( 60 $\mathrm{Hz}, 8 \mathrm{~ms}$ duration). Electrical stimuli were produced by a Grass S88 stimulator and applied through wire electrodes placed at the top and bottom of the bath chamber. Isotonic contractions were expressed as a percentage of the ring length. Isometric contractions in response to $\mathrm{ACh}$ were normalised per tissue cross sectional area of each preparation. Cross sectional area $\left(\mathrm{mm}^{2}\right)$ was calculated by an indirect method, ${ }^{21}$ with weight $(w)$ and length
(1) of the rings according to the formula:

cross sectional area $=\mathrm{w} /(1 \times \mathrm{D})$

where $1(\mathrm{~mm})$ represents the ring diameter measured in the bath after the equilibration period, $w(\mathrm{mg})$ is the ring fresh weight measured at the end of each experiment, and D is the tissue density, considered to be equal to 1 $\mathrm{mg} / \mathrm{mm}^{3}$. As the tissue stress generated by ACh did not show differences between bronchial rings from rats exposed to $\mathrm{NO}_{2}$ and controls (see results), we could express the isometric contractions in response to 5-HT and to electrical field stimulation as a percentage of the maximum response to $\mathrm{ACh}$ obtained in the same ring, thus reducing the magnitude of the statistical errors inherent in sampling and manipulation.

\section{DRUGS AND CHEMICALS}

Diazepam was obtained from Roche Pharmaceuticals (Basel, Switzerland), leptofen from Farmitalia Carlo Erba SpA (Milano, Italy). Evans blue dye, acetylcholine, and serotonin were obtained from Sigma Chemical (St Louis, MO, USA). Stock solutions for the study on bronchial responsiveness were made in water at concentrations 1000 -fold greater to minimise changes in bath volume, $\mathrm{pH}$, and ionic strength.

\section{DATA ANALYSIS}

Data relative to lung histology and airway microvascular leakage were expressed as medians (ranges). Data relative to bronchial smooth muscle response in vitro were expressed as mean (SEM), except for the concentration eliciting $50 \%$ of the maximum response $\left(\mathrm{EC}_{50}\right)$ which was expressed as geometric mean (GM) (GSEM), and 95\% confidence intervals (95\% CIs).

Results relative to lung histology and airway microvascular leakage were analysed by Mann-Whitney $U$ test. Results relative to bronchial smooth muscle response in vitro were compared by a one way analysis of variance (ANOVA) for repeated measures, and by unpaired Student's $t$ test. Differences were considered significant when the $P$ value was $<0.05$.

\section{Results}

\section{LUNG HISTOLOGY}

We found a significant increase in total inflammation at the level of respiratory bronchioles and alveoli in rats exposed to $10 \mathrm{ppm} \mathrm{NO}$ for seven days. Although we did not attempt a precise differential count of inflammatory cells, we found that cellular infiltrate was predominantly composed of mononuclear leucocytes (fig 1). Figure 2 shows the pathological scores for total tissue inflammation. By contrast, no significant difference in neutrophil tissue infiltration was found. The number of neutrophils in rats exposed to $10 \mathrm{ppm} \mathrm{NO}_{2}$ and air were respectively 0.18 (range $0.00-0.50$ ) and 0.00 (range $0.00-0.25$ ) cells/high power field in small airways $(z=$ $-1.01, \mathrm{P}=0.31$ by Mann-Whitney $U$ test), 
Figure 1

Photomicrographs of peripheral airways and lung parenchyma of a rat exposed to $(A)$ air and $(B)$ $10 \mathrm{ppm} \mathrm{NO}_{2}$. Arrows indicate the mononuclear leucocyte infiltrate in the tissue from the animal exposed to NO ${ }_{2}$. Stain: haematoxylin-eosin, light microscopy. Final magnification: $\times 400$
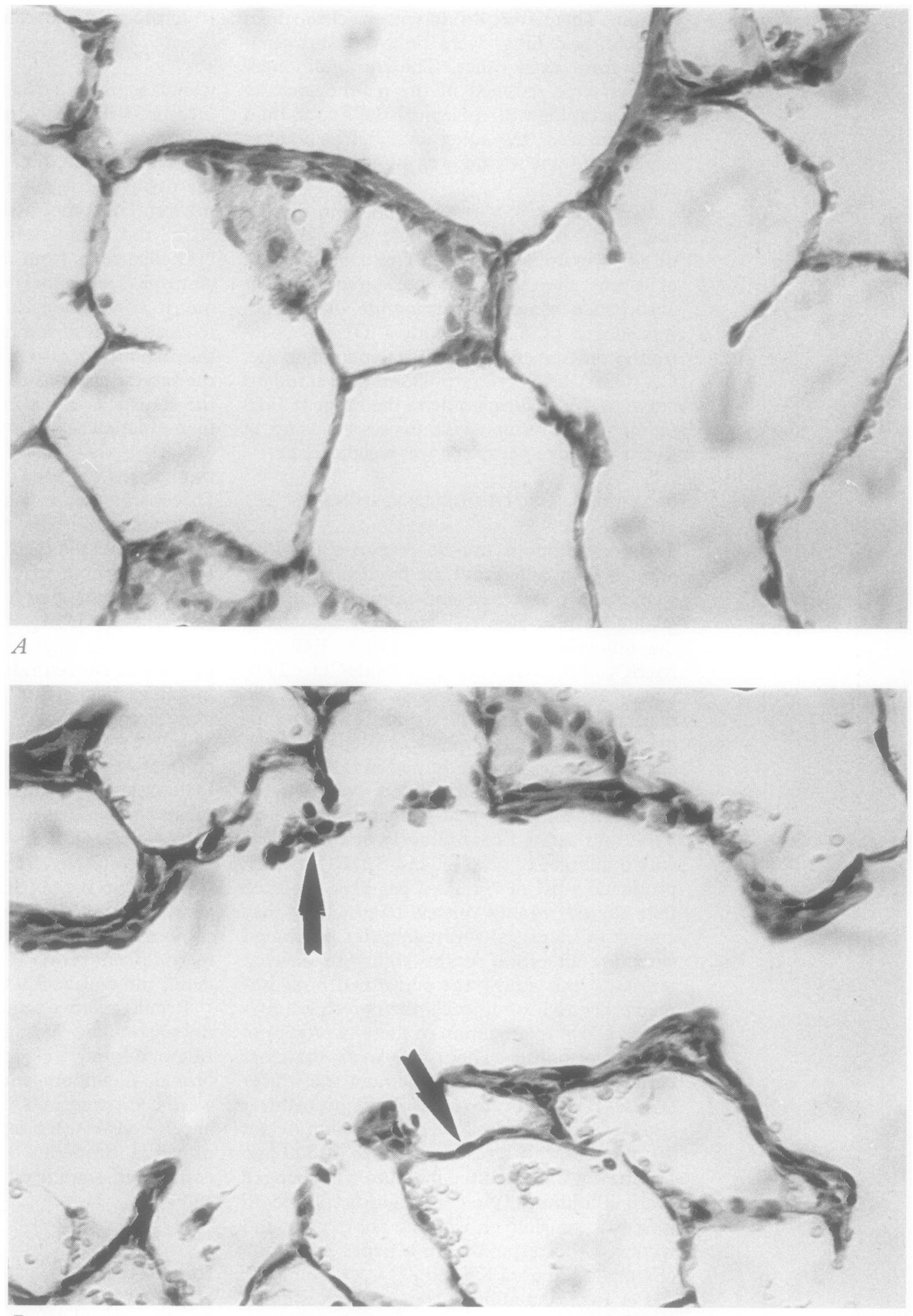

B

and 0.10 (range $0.00-0 \cdot 20$ ) and 0.08 (range $0 \cdot 00-0 \cdot 16)$ cells/high power field in the main bronchus $(z=-0.29, P=0.77$ by MannWhitney $U$ test).

We also found epithelial damage, with loss of cilia, and ectasia of alveolar capillaries. The scores for loss of cilia in the epithelial cells were 83.5 (range 33-100) and 0.0 (range 0.0-11) in animals exposed to $\mathrm{NO}_{2}$ and air respectively $(z=-2.31, \mathrm{P}=0.02$ by MannWhitney $U$ test). The distance between alveolar walls, as measured by Lm, was not different in rats exposed to $\mathrm{NO}_{2}$ and air, which were respectively 50.5 (range $45 \cdot 0-57 \cdot 0) \mu \mathrm{m}$ and 36.0 (range $30.0-50.0 \mu \mathrm{m}, z=-1.59, \mathrm{P}=$ $0 \cdot 11$ by Mann-Whitney $U$ test).

AIRWAY MICROVASCULAR LEAKAGE

Macroscopic observation of the tissue before the extraction of the Evans blue dye was similar for rats exposed to $\mathrm{NO}_{2}$ and air where only the vessels were notably stained. Measurement of Evans blue dye showed that plasma extravasation did not increase above control values in any site of the airways from rats exposed to $\mathrm{NO}_{2}$. Table 1 shows the concentrations of 
Table 1 Concentration of Evans blue dye in airways from rats exposed for seven days to $10 \mathrm{ppm} \mathrm{NO}$ and from control rats

\begin{tabular}{lll}
\hline & Exposed to $\mathrm{NO}_{2}$ & Controls \\
\hline Larynx & $11 \cdot 9(8 \cdot 1-14 \cdot 7)$ & $11 \cdot 0(8 \cdot 2-20 \cdot 7)$ \\
Trachea & $25 \cdot 1(23 \cdot 2-39 \cdot 2)$ & $27 \cdot 8(20 \cdot 8-38 \cdot 3)$ \\
Main bronchi & $56 \cdot 4(52 \cdot 8-64 \cdot 5)$ & $70 \cdot 7(42 \cdot 4-105 \cdot 8)$ \\
IPA & $26 \cdot 9(24 \cdot 8-34 \cdot 6)$ & $35 \cdot 1(16 \cdot 5-53 \cdot 2)$ \\
\hline
\end{tabular}

Data are medians (ranges) and are expressed as ng per $\mathrm{mg}$ of wet weight of tissue, $n=4$ for rats exposed to $\mathrm{NO}_{2}, n=8$ for controls. Mann-Whitney $U$ test values were: $z=-0 \cdot 17, P=$ 0.87 for larynx; $z=-0.34, P=0.73$ for trachea; $z=-0.78, P$ $=0.40$ for main bronchi; $z=-1.19, P=0.23$ for intrapulmonary airways (IPA).
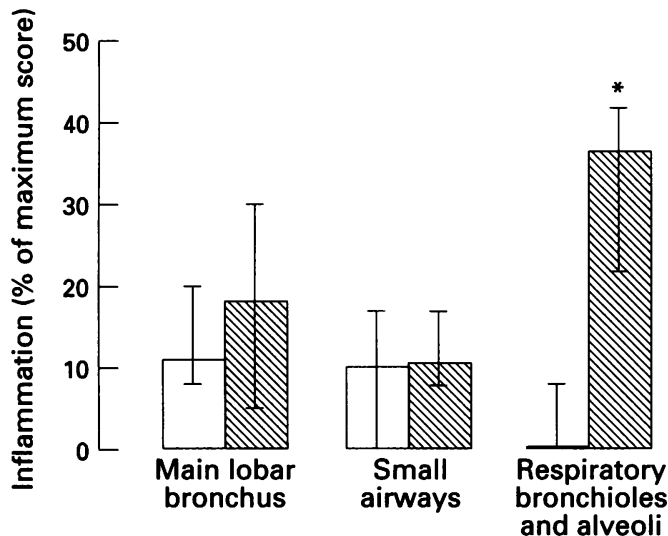

Figure 2 Total inflammation in the airway walls of rats exposed for seven days to filtered air (open columns) or to $10 \mathrm{ppm} \mathrm{NO}_{2}$ (hatched columns). Columns and bars represent medians and ranges, respectively. Asterisk indicates $P<0.05$ by Mann-Whitney U test $(z=-2.31$, $P=0.02$ ); for main lobar bronchus $z=0.87, P=0.39$, and for small airways $z=-0.43, P=0.67$.

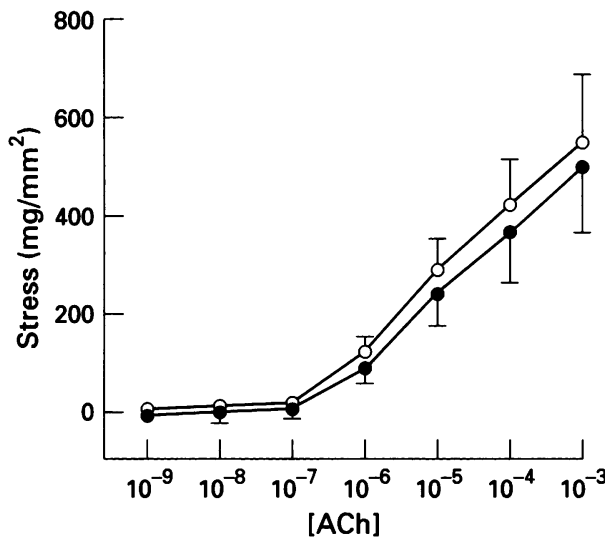

Figure 3 Isometric response to acetylcholine $(A C h)$ in rat main bronchi from animals exposed for seven days to filtered air (open circles, $n=12$ ) or $10 \mathrm{ppm} \mathrm{NO}$ (closed circles, $n=11$ ). Each point is mean (SEM), $F=0 \cdot 185$ $P=0.67$ by $A$ NOVA.

Table 2 Smooth muscle sensitivity ( $E C_{50}$ ) calculated from curves performed in isometric conditions in bronchi from rats exposed for seven days to $10 \mathrm{ppm} \mathrm{NO}_{2}$ and in control rats

\begin{tabular}{lcc}
\hline & Exposed to $\mathrm{NO}_{2}$ & Controls \\
\hline ACh (M) & $1 \cdot 3.10^{-5}(1 \cdot 4)$ & $7 \cdot 7.10^{-6}(1 \cdot 3)$ \\
$95 \%$ CI & $6 \cdot 0.10^{-6}$ to $2 \cdot 7.10^{-5}$ & $4 \cdot 1.10^{-6}$ to $1 \cdot 4.10^{-5}$ \\
$5-\mathrm{HT}(\mathrm{M})$ & $1 \cdot 4.10^{-6}(1 \cdot 6)$ & $7 \cdot 2.10^{-7}(1 \cdot 3)$ \\
$95 \%$ CI & $4 \cdot 7.10^{-7}$ to $4 \cdot 0.10^{-6}$ & $3 \cdot 9.10^{-7}$ to $1 \cdot 3.10^{-6}$ \\
Electrical field stimulation (V) & $16 \cdot 6(1 \cdot 0)$ & $16.5(0.9)$ \\
95\% CI & $14 \cdot 3$ to 18.9 & 14.5 to $18 \cdot 6$
\end{tabular}

The sensitivity of acetylcholine ( $\mathrm{ACh}$ ) and to serotonin (5-HT) is expressed as $\mathrm{EC}_{50}$ (geometric mean and GSEM), whereas sensitivity to electrical field stimulation is expressed as $\mathrm{EV}_{50}$ (mean (SEM)). Sample sizes for rats exposed to $\mathrm{NO}_{2}$ and controls were respectively $\mathrm{n}=11$ and $\mathrm{n}=12$ for ACh and 5-HT, $\mathrm{n}=8$ and $\mathrm{n}=9$ for electrical field stimulation. The test statistical values by Student's unpaired $t$ test were: $t=1.16, \mathrm{P}=0.26$ for $\mathrm{ACh} t=1.18, \mathrm{P}=0.25$ for $5-\mathrm{HT}$ $t=0.015, P=0.99$ for electrical field stimulation.
Evans blue dye in the airways of rats exposed to $\mathrm{NO}_{2}$ and air at the levels of the larynx, trachea, main bronchi, and intrapulmonary airways.

\section{SMOOTH MUSCLE RESPONSE}

Isometric conditions

Acetylcholine caused a concentration dependent isometric contraction of bronchial smooth muscle which was not altered by exposure to $10 \mathrm{ppm} \mathrm{NO}$ for seven days (fig 3); for this reason we expressed tension developed by electrical field stimulation and 5-HT as a percentage of the response to $1 \mathrm{mM}$ of $\mathrm{ACh}$. Exposure to $\mathrm{NO}_{2}$ did not alter the curves in response to 5-HT or electrical field stimulation, nor did it modify the maximum response. Figure 4 shows the isometric voltage-response curves to electrical field stimulation and the concentration-response curves to 5-HT for bronchi obtained from rats exposed to air and $\mathrm{NO}_{2}$. Table 2 shows the sensitivity to $\mathrm{ACh}$ and 5-HT expressed as $\mathrm{EC}_{50}$, and to electrical field stimulation expressed as $E V_{50}$, obtained from isometric curves.

\section{Isotonic conditions}

No change in the shape of the curve and in the maximum response after exposure to $\mathrm{NO}_{2}$ was found in isotonic experiments. Figure 4 shows the shortening produced isotonically that is dependent upon concentrations of $\mathrm{ACh}$ and 5HT in bronchi from rats exposed to filtered air or $10 \mathrm{ppm} \mathrm{NO} \mathrm{NO}_{2}$. Table 3 shows the sensitivity to $\mathrm{ACh}$ and 5-HT calculated from concentration-response curves performed isotonically.

\section{Discussion}

In the present study we found an increased total inflammation at the level of respiratory bronchioles and alveoli after seven day in vivo exposure to $10 \mathrm{ppm} \mathrm{NO}_{2}$. No influx of inflammatory cells was found in the main bronchi. We also found loss of cilia from the epithelial cells and ectasia of alveolar capillaries. By contrast, we found no enlargement of the airspaces, no alteration of microvascular permeability in the larynx, trachea, main bronchi, and intrapulmonary airways, and no modification of bronchial smooth muscle contractile response to acetylcholine, electrical field stimulation, and serotonin.

In different animal species the inflammatory response induced by $\mathrm{NO}_{2}$, which is more pronounced in peripheral airways and alveoli, consists of an initial increase in neutrophils, followed by macrophage and lymphocyte infiltration. The influx of alveolar macrophages and lymphocytes reaches a maximum after one week of exposure or more, although it has also been reported at earlier times. ${ }^{722}$

The results of the present study are in agreement with our previous report from bronchoalveolar lavage, ${ }^{16}$ and confirm that the inflammatory response and the structural damage occur distally in the airways and in the alveoli, at least at the concentrations of $\mathrm{NO}_{2}$ we have used. As $\mathbf{N O}_{2}$ is a gas with low solubility, it is poorly absorbed by the airway 
Figure 4 Isometric (5-HT) in rat main bronchi from animals exposed for seven days to filtered air (open circles, $n$ $=9$ for electrical field stimulation and $n=12$ for 5-HT) or $10 \mathrm{ppm} \mathrm{NO}_{2}$ (closed circles, $n=8$ for electrical field stimulation and $n=11$ for $5-H T$ ).

Each point is mean

(SEM), $F=0.168, P=$ 0.69 for electrical field $P=0.99$ for $5-H T$ by ANOVA. responses to electrical field stimulation and to serotonin stimulation and $F=5 \cdot 76$,

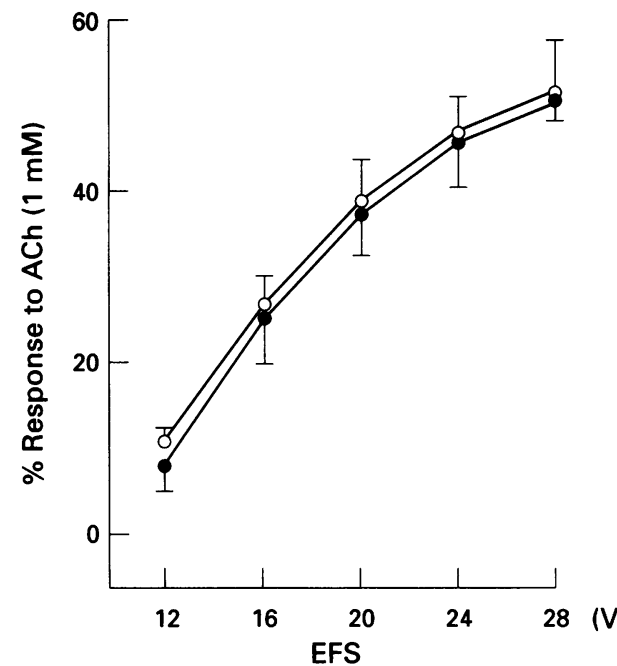

Table 3 Smooth muscle sensitivity $\left(E C_{50}\right)$ calculated from curves performed in isotonic conditions in bronchi from rats exposed for seven days to $10 \mathrm{ppm} \mathrm{NO}_{2}$ and in control rats

\begin{tabular}{cll}
\hline & Exposed to $\mathrm{NO}_{2}$ & Controls \\
\hline ACh (M) & $1 \cdot 0.10^{-5}(1 \cdot 3)$ & $5 \cdot 7.10^{-6}(1 \cdot 4)$ \\
$95 \%$ CI & $5 \cdot 0.10^{-6}$ to $2 \cdot 0.10^{-5}$ & $2 \cdot 5.10^{-6}$ to $1 \cdot 3.10^{-5}$ \\
$5-\mathrm{HT}(\mathrm{M})$ & $3 \cdot 5.10^{-7}(1 \cdot 8)$ & $6 \cdot 8.10^{-7}(1 \cdot 3)$ \\
$95 \% \mathrm{CI}$ & $9 \cdot 0.10^{-8}$ to $1 \cdot 3.10^{-6}$ & $3 \cdot 4.10^{-7}$ to $1 \cdot 4.10^{-6}$ \\
\hline
\end{tabular}

The sensitivity to acetylcholine (ACh) and to serotonin (5-HT) is expressed as EC $_{50}$ (geometric mean and GSEM). For each group $\mathrm{n}=8$. Values were tested by Student's unpaired $t$ test and were for ACh and 5-HT respectively $t=1 \cdot 24, \mathrm{P}=0.23$ and $t=-1 \cdot 05, \mathrm{P}=0.31$.

mucosa. Nevertheless, its uptake in the respiratory system is extremely high (because of its reactivity) and is maximum at the level of the terminal bronchioles. ${ }^{3}$

Like inflammation, lung oedema induced by $\mathrm{NO}_{2}$ is mainly reported in small airways and alveolae, is more evident during early exposure, and declines with time. ${ }^{78}$

In the present study we used a method which has been shown to be particularly sensitive in detecting exudation of plasma into the airway tissue. ${ }^{23}$ We found no alteration of microvascular permeability after seven days of continuous exposure to $\mathrm{NO}_{2}$, although we have previously shown that with the same method the concentration of Evans blue dye increases more than twofold over basal levels after giving $1 \mu \mathrm{g} / \mathrm{kg}$ of platelet activating factor. ${ }^{24}$ These findings may depend on the time course of the alteration of vascular permeability

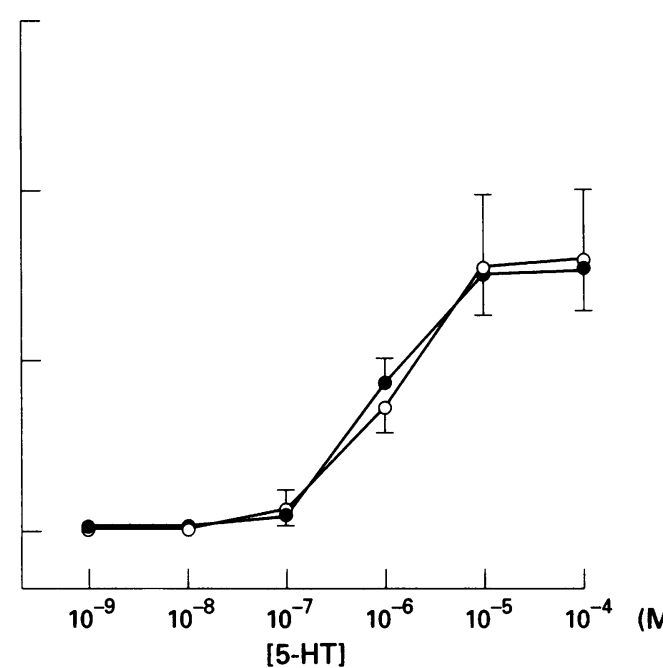

induced by $\mathrm{NO}_{2}$, which could indeed be back to baseline at the time point we studied. Were this the case, the observed swelling of septal capillaries would represent a late or persistent morphological alteration. Alternatively, we could speculate that the exposure to $10 \mathrm{ppm}$ $\mathrm{NO}_{2}$ is too low to cause a persistent microvascular leakage and that ectasia of alveolar capillaries is a more suitable index of the effects of $\mathrm{NO}_{2}$ on vessels.

The considerations we have made about microvascular leakage may also apply to our results on the contractile response of bronchial smooth muscle as the fact that it was not altered by $\mathrm{NO}_{2}$ could possibly depend on the time course or on the need of a higher level of exposure for this effect to be produced. However, several other factors may possibly be responsible.

The fact that airway hyperresponsiveness induced by $\mathrm{NO}_{2}$ has been inconsistently reported may be due to either differences in the exposed populations - that is, the possible existence of a group of responders and one of non-responders - or to a different strain or species susceptibility. The recent finding in mice that some inbred strains develop airway hyperresponsiveness to intravenous acetylcholine after exposure to $\mathrm{O}_{3}$, whereas some others do not, ${ }^{25}$ further supports the possibility of a differential susceptibility to oxidant haz-
Figure 5 Isotonic responses to acetylcholine $(A C h)$ and to serotonin (5-HT) in rat main bronchi from animals exposed for seven days to filtered air (open circles, $n$ $=8$ ) or $10 \mathrm{ppm} \mathrm{NO}_{2}$ (closed circles, $n=8$ ). Each point is mean (SEM), $F=0.011, P=$ 0.92 for $A C h$ and $F=$ $2 \cdot 59, P=0.13$ for $5-H T$ by $A N O V A$.
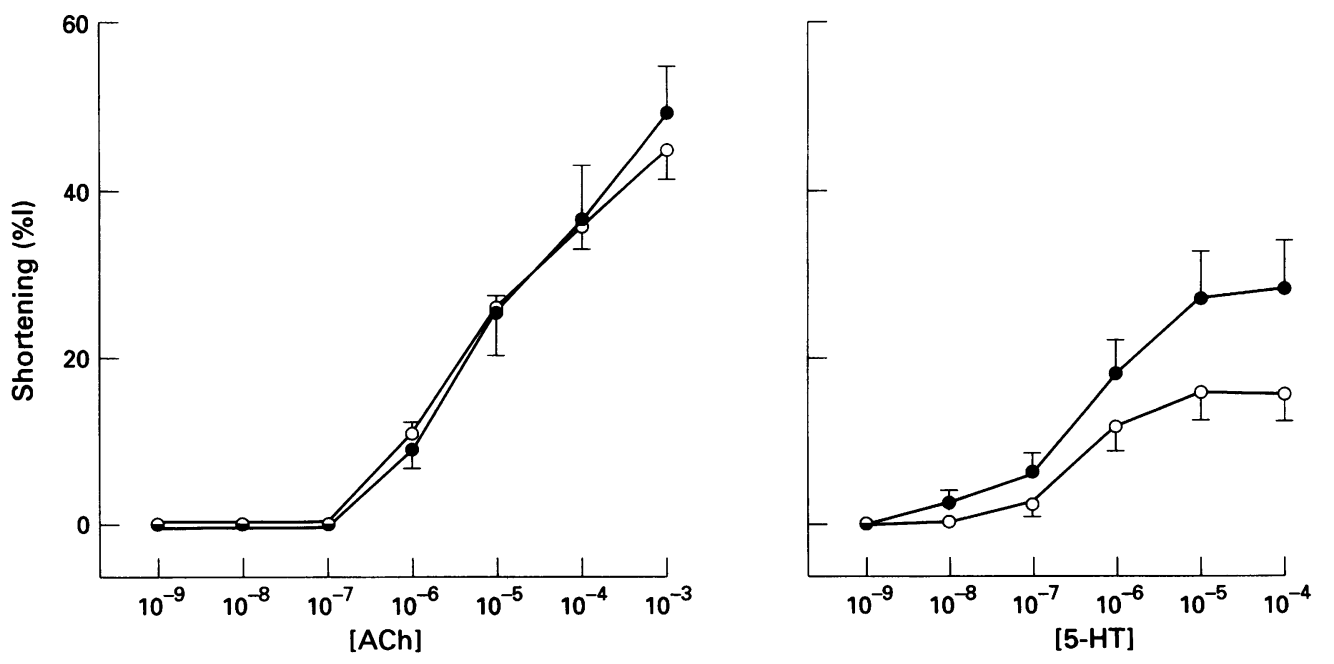
ard. Also, a quantitative difference in lung lipid peroxidation and antioxidative protective system activity after exposure to $\mathrm{NO}_{2}$ has been found between rats and guinea pigs. ${ }^{26}$

It is possible that our negative results, as well as the inconsistency of data on humans, depend on several factors, which may differ between subjects or species. Firstly, nitric oxide, a potent relaxant of smooth muscle, has been identified as a metabolic product of $\mathrm{NO}_{2}$ exposure. ${ }^{27}$ The formation of this compound could prevent development of hyperresponsiveness by reducing the basal tone and therefore the contractility of the smooth muscle. Secondly, it has been shown that tolerance may develop after repeated exposure to oxidant agents, ${ }^{28}$ so individual history could influence the functional effects. Even though the concept of tolerance refers more properly to repeated exposures, protective compensatory mechanisms may also develop during a single continuous exposure, as shown by the increase of protective enzymatic activity found in rats after about five days of continuous exposure to $\mathrm{NO}_{2}{ }^{29}$ Finally, the contemporary or previous exposure to other pollutants may be necessary for the development of airway hyperresponsiveness, as synergism between $\mathrm{NO}_{2}$ and other pollutant substances has been shown. ${ }^{26}$

It has been suggested that bronchial hyperresponsiveness may be caused by inflammatory mediators. ${ }^{30}$ In the present study we found an inflammatory infiltrate in small airways and alveoli, but not in the main bronchi, and we found no alteration of smooth muscle responsiveness in main bronchi. It is therefore possible that an increase of smooth muscle responsiveness was not detected because it occurs peripherally to the main bronchi. Further studies will be required to elucidate the role of the factors we have discussed and to identify those most influential in the development of hyperresponsiveness as a consequence of exposure to $\mathrm{NO}_{2}$.

We finally need to consider the complexity of the events leading to airway hyperresponsiveness and the multitude of factors which contribute to its development. In fact, in vivo airway hyperresponsiveness may be affected by factors such as secretions, neural reflexes, and parenchymal elastic recoil, which do not influence smooth muscle response in vitro. Those factors may be responsible for the frequently found absence of correlation between airway responsiveness in vivo and smooth muscle responsiveness in vitro. ${ }^{31}$ In the present study, as for every study on isolated smooth muscle, we intended to reduce the number of components contributing to airway responsiveness, with the aim of investigating the involvement of smooth muscle alterations in the hyperresponsiveness induced by $\mathrm{NO}_{2}$. Therefore, a possible explanation for our negative results would be that the in vivo airway hyperresponsiveness is affected by alterations of nonmuscular factors contributing to the bronchospasm, which would not be detectable by our approach.

In summary, we have found that subchronic exposure to up to $10 \mathrm{ppm} \mathrm{NO}_{2}$ causes airway inflammation and structural damage but does not alter microvascular permeability and bronchial smooth muscle responsiveness in rats.

This work was funded in part by the NRC-ENEL ProjectInteractions of Energy Systems with Human Health and Environment, Roma, NRC FATMA Project No 92.00233.PF41 and 93.00650.PF41, NRC bilateral project, Italy and France, MURST, European Commission (Biomedical and Health Research Programme BMH 1, CT 94-1281), and ASTMP, Padova. We thank Carol Howarth for the editorial handling of the manuscript, Luigi Zedda for the drawing of the figures, and Massimo Lanfredi for techr drawing of the figures, and Massimo Lanfredi for technical Paolo Pagani for their useful contribution to the study.

1 Fishbein L. Sources, nature and levels of air pollutants. In: Tomatis L, ed. Indoor and outdoor air pollution and human cancer. Berlin Heidelberg: Springer-Verlag, 1993: 17-66.

2 Boström CE. Nitrogen oxides in ambient air-properties, sources and concentrations. Scand $\mathcal{F}$ Work Environ Health 1993;19(suppl 2):9-13.

3 Chitano P, Hosselet J, Mapp CE, Fabbri LM. Effect of oxidant air pollutants on the respiratory system: insights oxidant air pollutants on the respiratory system: insights from exp

4 Magnussen $\mathrm{H}$. Experimental exposure to nitrogen dioxide. Eur Respir f 1992;5:1040-2

5 Bylin G. Controlled studies on humans. Scand $\mathcal{f}$ Work Environ Health 1993;19(suppl 2):37-43.

6 Sandström T, Stjernberg N, Eklund A, Ledin MC, Bjermer $\mathrm{L}$, Kolmodin-Hedman B, et al. Inflammatory cell response in bronchoalveolar lavage fluid after nitrogen dioxide exposure of healthy subjects: a dose-response study. Eur Respir $\mathcal{F}$ 1991;3:332-9.

7 Glasgow JE, Pietra GG, Abrams WR, Blank J, Oppenheim DM, Weinbaum G. Neutrophil recruitment and degranulation during induction of emphysema in the rat by nitrogen dioxide. Am Rev Respir Dis 1987;135:1129-36.

8 Kawakami M, Yasui S, Yamawaki I, Katayama M, Nagai A, Takizawa T. Structural changes in airways of rats exposed to nitrogen dioxide intermittently for seven days. Comparison between major bronchi and terminal bronchioles. Am Rev Respir Dis 1989;140:1754-62.

9 Orehek J, Massari JP, Gaynard P, Grimaud C, Charpin J. Effect of short-term, low-level nitrogen dioxide exposure on bronchial sensitivity of asthmatic patients. $₹$ Clin Invest 1976;57:301-7.

10 Morrow PE, Utell MJ, Bauer MA, Smeglin AM, Frampton MW, Cox C, et al. Pulmonary performance of elderly normal subjects and subjects with chronic obstructive pulmonary disease exposed to $0.3 \mathrm{ppm}$ nitrogen dioxide. pulmonary disease exposed to 0.3 ppm

11 Silbaugh SA, Mauderly JL, Macken CA. Effects of sulphuric acid and nitrogen dioxide on airway responsiveness of guinea pig. $\mathcal{F}$ Toxicol Environ Health 1981;8 $31-45$.

12 Kobayashi T, Shinozali Y. Effect of subacute exposure to nitrogen dioxide on the airway responsiveness of guinea pig. Agent Actions 1990;31(suppl):71-4.

13 Ben-Jebria A, Marthan R, Savineau JP. Effect of in vitro nitrogen dioxide exposure on human bronchial smooth muscle response. Am Rev Respir Dis 1992;146:378-82.

14 Chitano P, Papi A, Lucchini RE, Coser E, Saetta M, Maestrelli $\mathrm{P}$, et al. In-vitro exposure to nitrogen dioxide $\left(\mathrm{NO}_{2}\right)$ does not alter bronchial smooth muscle responsiveness in ovalbumin-sensitized guinea pigs. Pulm Pharmacol 1994;7:251-7.

15 Chitano P, Lucchini RE, Coser E, Papi A, Saetta M, Maestrelli $P$, et al. In-vitro exposure of guinea pig main bronchi to $2.5 \mathrm{ppm}$ of nitrogen dioxide does not alter airway smooth muscle response. Respir Med 1995;89:323-8.

16 Pagani P, Romano M, Erroi A, Ferro M, Salmona M Biochemical effects of acute and subacute nitrogen dioxide exposure in rat lung and bronchoalveolar lavage fluid. Arch Environ Contam Toxicol 1994;27:426-30.

17 Romano M, Pagani P, Ferro M, Erroi A, Moggi M, Barozzi $\mathrm{F}$, et al. An automated system for animal exposure to nitrogen dioxide. $\mathcal{F}$ Pharmacol Toxicol Methods 1994;31: nitrogen

18 Cosio MG, Ghezzo H, Hogg JC, Corbin R, Loveland M, Dosman J, Macklem PT. The relations between structural changes in small airways and pulmonary function tests. N Engl f Med 1977;298:1277-81.

19 Thurlbeck WM. The internal surface area of non-emphysematous lungs. Am Rev Respir Dis 1967;95:765-73.

20 Stephens NL, Jiang H, Xu J, Kepron W. Airway smooth muscle mechanics and biochemistry in experimental muscle mechanics and biochemistry in

21 Herlihy JT, Murphy RA. Length-tension relationship of smooth muscle of the hog carotid artery. Circ Res 1973; 33:275-83.

22 Kleinerman J, Ip MPC, Sorensen J. Nitrogen dioxide exposure and alveolar macrophage elastase in hamsters. $\mathrm{Am}$ sure and alveolar macrophage

23 Rogers DF, Boschetto P, Barnes PJ. Plasma exudation. Correlation between Evans blue dye and radiolabeled albumin in guinea pig airways in vivo. $f$ Pharmacol Methods 1989;21:309-15.

24 Boschetto P, Musajo FG, Tognetto L, Boscaro M, Mapp $\mathrm{CE}$, Barnes PJ, Fabbri LM. Increase in vascular perme- 
ability produced in rat airways by PAF: potentiation by adrenalectomy. Br f Pharmacol 1992;105:388-92.

25 Zhang LY, Levitt RC, Kleeberger SR. Differential susceptibility to ozone-induced hyperreactivity in inbred stains of mice. American foumal of Respiratory Critical Care Medicine 1994;149:A157.

26 Ichinose T, Sagai M. Biochemical effects of combined gases of nitrogen dioxide and ozone. III. Synergistic gases of nitrogen dioxide and ozone. III. Synergistic systems in the lungs of rats and guinea pigs. Toxicology systems in the lung

27 Maples KR, Sandström T, Su YF, Henderson RF. The nitric oxide/heme protein complex as a biologic marker of exposure to nitrogen dioxide in humans, rats, and in vitro models. Am $\mathcal{~ R e s p i r ~ C e l l ~ M o l ~ B i o l ~ 1 9 9 1 ; 4 : 5 3 8 - 4 3 . ~}$

28 Mustafa MG, Tierney DF. Biochemical and metabolic changes in the lung with oxygen, ozone, and nitrogen dioxide toxicity. Am Rev Respir Dis 1978;118:1061-90.

29 Sagai M, Ichinose T, Oda H, Kubota K. Studies on biochemical effects of nitrogen dioxide. II. Changes of the protective systems in rat lungs and of lipid peroxidation by acute exposure. $\mathcal{f}$ Toxicol Environ Health 1982;9: 153-64.

30 Daniel EE, O'Byrne P. Autonomic nerves and airway smooth muscle. Effect of inflammatory mediators on airway nerves and muscle. Am Rev Respir Dis 1991;143 (suppl):S3-5.

31 De Jongste JC, Sterk PJ, Willems LNA, Mons H, Timmers MC, Kerrebijn KF. Comparison of maximal bronchoconstriction in vivo and airway smooth muscle response in vitro in non-asthmatic humans. Am Rev Respir Dis 1988;138:321-6.

\section{Vancouver style}

All manuscripts submitted to Occup Environ Med should conform to the uniform requirements for manuscripts submitted to biomedical journals (known as the Vancouver style.)

Occup Environ Med, together with many other international biomedical journals, has agreed to accept articles prepared in accordance with the Vancouver style. The style (described in full in the BMF, 24 February $1979, p$ 532) is intended to standardise requirements for authors.

References should be numbered consecutively in the order in which they are first mentioned in the text by Arabic numerals above the line on each occasion the reference is cited (Manson ${ }^{1}$ confirmed other reports $^{2-5} \ldots$. .). In future references to papers submitted to Occup Environ Med should include: the names of all authors if there are seven or less or, if there are more, the first six followed by et al; the title of journal articles or book chapters; the titles of journals abbreviated according to the style of Index Medicus; and the first and final page numbers of the article or chapter. Titles not in Index Medicus should be given in full.

Examples of common forms of references are:

1 International Steering Committee of Medical Editors, Uniform requirements for manuscripts submitted to biomedical journals. Br Med $\Im$ 1979;1:532-5.

2 Soter NA, Wasserman SI, Austen KF. Cold urticaria: release into the circulation of histamine and eosinophil chemotactic factor of anaphylaxis during cold challenge. N Engl $\mathcal{Y}$ Med 1976;294:687-90.

3 Weinstein L, Swartz MN. Pathogenic properties of invading micro-organisms. In: Sodeman WA Jr, Sodeman WA, eds Pathologic physiology, mechanisms of disease. Philadelphia: W B Saunders, 1974:457-72. 